\title{
Unipolaridade, governabilidade global e intervenção unilateral anglo-americana no Iraque
}

\begin{tabular}{lr} 
EDUARDO VIOLA* \\
\hline Rev. Bras. Polit. Int. 47 (2): 29-58 [2004] \\
HÉCTOR RICARDO LEIS**
\end{tabular}

Introdução

O fato de determinadas idéias, que contradizem grosseiramente o real, se terem imposto como um "horizonte inultrapassável" constitui um dos traços mais espantosos da cultura dos nossos dias.

Raymond Boudon (1998: 272)

Neste artigo pretendemos relacionar três problemáticas conceituais - a do caráter unipolar do sistema internacional desde o início dos anos 90, a da governabilidade global do mundo e a do unilateralismo em relação às questóes de segurança coletiva - acerca de um evento histórico, a intervenção militar no Iraque pela coalizão anglo-americana em 2003. Neste sentido, entendemos por unipolar um sistema internacional no qual existe uma concentração de riqueza e poder numa potência que não tende a ser contestado por uma coalizão de todas as outras potencias relevantes. Isto quer dizer que o sistema internacional continua sendo

\footnotetext{
* Professor titular de Relaçôes Internacionais da Universidade de Brasília (UnB).

** Professor adjunto do Departamento de Sociologia e Ciência Política da Universidade Federal de Santa Catarina (UFSC).
} 
essencialmente anárquico (embora menos que no passado por causa da interdependência crescente da globalização econômica e tecnológica) e que não deve ser confundido com anarquia hobbesiana nem com um governo mundial do tipo kantiano. O mundo unipolar constituísse pela combinação do repentino colapso da União Soviética, do extraordinário dinamismo da economia americana e da estagnação econômica alemã e japonesa. Circunstâncias estas que pegaram de surpresa até as próprias elites americanas. De uma forma realista, entendemos por governabilidade global as políticas e as normas que permitem administrar os diversos problemas econômicos, políticos e sociais mundiais a partir de uma estrutura hierárquica de potências. Organizaçóes internacionais como as Nações Unidas têm um papel limitado e secundário do ponto de vista da governabilidade global. Por último definimos intervenção unilateral em relação a um comportamento político-militar, fora do direito internacional, da potência hegemônica no sistema internacional (de tal forma que fica excluída qualquer outra intervenção militar ilegal que não envolva a potência hegemônica).

\section{A colonização idealista de uma área tradicionalmente realista}

Quando o secretário de Defesa do governo Bush, Donald Rumsfeld, no dia da entrada em Bagdá das forças de coalizão anglo-americana e da conseqüente derrubada do regime de Saddam Hussein reclamou da mídia porque não havia manchetes que fizessem referência à libertação do povo iraquiano de uma longa e sangrenta ditadura, ele estava registrando algo mais que uma queixa. ${ }^{1}$ Chamando a atenção para o fato dos jornais nesse dia terem concentrado sua atenção no sofrimento dos habitantes de Bagdá, submetidos ao caos resultante de um grande número de saques e roubos, Rumsfeld estava constatando um fato que ultrapassava as notícias do dia. Ciente, ou não, das implicações de sua declaração, ele estava registrando um fato que continua a passar praticamente despercebido, apesar de sua enorme relevância: o retrocesso histórico da mentalidade dominante nos países ocidentais. Em outras palavras, se aos olhos da mídia importa mais noticiar o caos social de uma cidade que a supressão da tirania despótica

\footnotetext{
${ }^{1}$ Ver RUMSFELD, Donald. Conferência de Prensa no Pentágono. 11 abr 2001. Disponível em: $<$ http://www.defenselink.mil>.
} 
que governava o país na qual se encontra essa cidade, isto quer dizer que a mentalidade ocidental está sofrendo um retrocesso em termos dos valores históricos tradicionais que guiaram a evolução política do Ocidente.

Se nos perguntamos, como um exemplo, o que diria o cidadão médio de qualquer grande cidade européia nos séculos XVIII e XIX sobre um fato equivalente de sua época, veríamos que, independentemente de suas ideologias e motivações, ele certamente concordaria com Rumsfeld, no sentido de que se deve dar prioridade ao fato político e social libertador, em relação ao atraso e ao despotismo, apesar dos eventuais sofrimentos humanos que possam acontecer no curto prazo. Tanto Kant, quanto Marx (tomados aqui como exemplos paradigmáticos dos extremos do espectro civilizatório da primeira modernidade), não vacilariam em apoiar decididamente acontecimentos políticos que possuíssem um conteúdo marcadamente progressivo em relação ao futuro, ainda quando eles mesmos não concordassem em absoluto com as intenções postas em prática pelos seus protagonistas.

Apesar de estar perfeitamente ciente do terror produzido pela Revolução Francesa, em $O$ conflito das faculdades (publicado em 1798), Kant afirma:

(...) esta Revolução, digo, encontra no espírito de todos os espectadores (que não estão eles mesmos enredados neste jogo) uma simpatia de aspirações que beira o entusiasmo - cuja manifestação seria perigosa e não poderia ter outra causa senão uma disposição moral no gênero humano. (Kant, 1963: 109).

Do mesmo modo, em defesa insuspeita do intervencionismo do imperialismo inglês, Marx conclui seu texto $A$ dominação britânica na India (publicado em 1853) com as seguintes palavras:

é verdade que a Inglaterra, ao provocar uma revolução social no Hindustão, era guiada pelos interesses mais abjetos e agia de uma maneira estúpida para atingir seus objetivos. Mas a questão não é essa. Trata-se de saber se a humanidade pode cumprir seu destino sem uma revolução fundamental na situação social da Ásia. Senão, quaisquer que fossem os crimes da Inglaterra, ela foi um instrumento da História ao provocar esta revolução. Nesse caso, diante de qualquer tristeza que possamos sentir diante do espetáculo do colapso de um mundo antigo, temos o direito de exclamar 
como Goethe: "Deve esta dor nos atormentar/ já que ela nosso proveito aumenta, / $\mathrm{O}$ jugo de Timur não consumiu miríades de vidas humanas? (Marx, 1977 (vol. 1): 359).

Vico ensinou que a historia é feita de corsi e ricorsi, o qual vale tanto para processos como para mentalidades. A sociologia do conhecimento mostra que até o século XVI as pessoas entendiam a história de forma muito diferente que na época de Kant e Marx. Ao contrario do que aconteceria posteriormente, o público contemporâneo de Maquiavel preferia interpretar a história por meio de normas morais, deixando para um segundo plano os próprios fatos; em outras palavras, a história era lida tendo em mente preceitos retóricos antes que científicos (Burke, 2003). Comprova-se hoje que os tempos voltaram a mudar e os fantasmas doutrinários, que assolaram Maquiavel há muitos séculos, nas últimas décadas se levantaram das tumbas. Este ressurgimento de antigos fantasmas deve ser cuidadosamente analisado, já que a distorção na percepção dos fatos históricos é em si mesmo um fato de primeira magnitude, tão inesperado quanto poderoso.

No século XX, com a exceção dos Estados Unidos e do Reino Unido, nos demais países ocidentais os estudos das relações internacionais atraíram escassa atenção no campo das ciências sociais. A problemática das dificuldades internacionais convocava apenas um pequeno grupo de especialistas, dos quais a maioria formava parte da diplomacia. Talvez por isso, quando o fenômeno da globalização começou a ser percebido, nos países periféricos não faltaram analistas que a trataram como ideologia pretensamente neocolonialista, mas não de um fato. É bom lembrar esta barbárie conceitual porque, embora esteja atualmente superada, ela é demonstrativa dos problemas que normalmente se encontram nesta área. Hoje não resta dúvida da importância dos fenômenos da globalização, a qual pode ser facilmente constatada no campo das ciências sociais observando a crescente atenção que os problemas globais (políticos, sociais, ambientais, etc.) vêm recebendo na última década por parte desses cientistas. Assim, com pouco ou nenhum background especializado na área de relações internacionais, é freqüente agora encontrar autores provenientes da sociologia (ou inclusive da antropologia) pesquisando e escrevendo sobre temas globais ou internacionais. Isto poderia ser 
motivo de alegria epistemológica se realmente estivesse frente a um esforço assumido interdisciplinarmente porém, infelizmente, é tudo o contrário. O bom observador pode comprovar hoje que as correntes e preocupações teóricas que dominam as ciências sociais são praticamente trasladadas ao campo de estudos das relaçóes internacionais sem qualquer revisão crítica. Assim, com a mesma "leveza" que antes se negava a existência da globalização e outros fenômenos conexos, agora os problemas são estudados com uma ótica semelhante à que se pesquisa um movimento social ou os problemas do self contemporâneo. A revisão crítica mencionada deveria ser obrigatória, até porque o campo teórico das ciências sociais se constituiu em suas origens por meio de diversos reducionismos que operaram uma descaracterização e uma redução da esfera da ação dos Estados como protagonistas da vida social, em geral, e das relações internacionais, em particular. Assim, o que temos hoje não é tanto um enriquecimento da pesquisa e debate neste campo a medida em que as perspectivas tradicionalmente normativas e militantes que predominam nas ciências sociais contemporâneas estão colonizando perigosamente os estudos das relaçóes internacionais.

A análise das relações internacionais exige um máximo de realismo (Luttwak 1999, Buzan 2002, Friedman 2002, Friedman 2003). Mas o realismo não é uma teoria entre outras. Antes de ser uma teoria, o realismo é uma perspectiva que constrói seus marcos normativos com base na história e não de disciplinas especulativas. Nesta área, o pesquisador precisa de um trabalho prévio de despojamento dos dogmatismos filosóficos e religiosos de sua época para atingir mínimas bases científicas. A cegueira intelectual deriva não tanto da escassez de princípios categóricos sobre como "deve ser" a realidade, mas de sua abundância. Infelizmente, nas últimas décadas as ciências sociais têm sido dominadas por correntes militantes que se confundem em boa medida com as posições éticas e teológicas dos atores da sociedade civil. Além de intérpretes engajados, hoje os cientistas sociais correm o risco de mimetizar-se com as açôes de atores concretos. Neste contexto, não é difícil comprovar que o realismo resulta de um bem cada vez mais escasso. No Brasil existem quatro fontes e também partes integrantes do idealismo normativo. Em primeiro lugar, temos a suposição que o atual sistema internacional é injusto por estar baseado na exploração 
dos países pobres e que deveria ser mudado baseado na justiça social entre os povos e na democracia entre os Estados, sendo que esta visão é partilhada pelas subculturas marxista, desenvolvimentista keynesiana e católica. Em segundo lugar, temos a suposição que a economia de livre mercado neoliberal é um instrumento de dominação americana do mundo, que pode ser contestada e que tende a diminuir junto com o declínio dos Estados Unidos, baseado numa assertiva quase metafísica de que "todo império perecerá". Em terceiro lugar, temos a suposição que o Brasil - pelo seu peso territorial, demográfico, econômico, ecológico e cultural - poderia, e deveria, ter um lugar mais destacado no sistema internacional caso houvesse uma política externa agressiva, sendo este voluntarismo muito mais presente nos políticos, militares e intelectuais e menos nos diplomatas que conhecem os constrangimentos do sistema. Em quarto lugar, temos a suposição que a norma jurídica internacional é capaz de produzir a realidade (numa réplica do imaginário do paradigma da Constituição de 1988), o que é alimentado por um processo de formação de opinião internacional nas elites, em que pesam mais os juristas e os economistas keynesianos, e menos os economistas de formação neoclássica - estes são os fundamentos da abordagem realista nas relações internacionais (Viola \& Pio 2003).

Existem boas razōes para acreditar que uma parte importante dos problemas de nossa época tem suas raízes em idéias políticas modernas. Independentemente dos méritos epistemológicos da ciência da modernidade em relação à da pré-modernidade, no seio da civilização ocidental foram introduzidas premissas que distorcem fortemente a realidade. Premissas que, entre outras coisas, levam a imaginar a realização de uma sociedade universal que suporia liberdade e igualdade para todos os indivíduos, a existência de uma comunidade internacional integrada por Estados também livres e iguais, além de justiça, felicidade e riqueza para todos (ver, entre outros: Strauss, 1953; Voegelin, 1978). Assumindo como um problema o otimismo exagerado desse projeto, parece oportuno revisar os supostos iluministas que dificultam, especialmente, a compreensão da política mundial. Alem da visível (e incrível) resistência ideológica do princípio de soberania nacional, existem outras duas questões não menos fundamentais que não aparecem suficientemente explicitadas no cenário teórico da área. A primeira é a presença clara de 
um forte iluminismo por trás da maioria das análises contemporâneas. Observe-se, por enquanto, que embora as visões iluminista da sociedade e da política sejam antigas, elas cobraram grande ímpeto às sombras do fim da Guerra Fria. Curiosamente, apesar da filosofia iluminista e do principio da soberania nacional pertencerem a paradigmas opostos (idealismo, por um lado, e realismo, por outro), após a Guerra Fria, na visão de muitos analistas contemporâneos, ambos elementos foram acomodados lado a lado sem problemas. Mas existe uma outra questão, relativamente associada à anterior, que também passou despercebida e cujo peso não é menos importante ao analisar a política mundial. Trata-se da extrapolação do vínculo existente entre ética e política, especificamente na esfera do Estado democrático, para o campo das relaçôes internacionais em geral. Certamente, a crescente presença do argumento ético-moral sobre o argumento estritamente político na esfera das relações internacionais tem algum suporte na realidade, especialmente se for considerado que os anos 80 e 90 foram testemunhas de significativos processos de transição para a democracia nos países do Leste Europeu e da União Soviética, mas as explicações desse fenômeno devem ir mais longe.

Do ponto de vista explicativo, estas duas questôes (a do iluminismo idealista e da ética aplicada às relações internacionais) se reforçam mutuamente, na medida em que estão sujeitas a uma mesma racionalidade utópica e societalista (isto é, focalizada mais na lógica do comportamento da sociedade civil do que dos Estados). As conseqüências para o campo de estudo das relações internacionais não poderiam ser maiores. Isto supõe, como já foi dito, uma colonização da área de conhecimento específica das relações internacionais pelas problemáticas das ciências sociais, em particular da sociologia. Esta colonização se torna evidente a propósito do tema da guerra, especialmente nos países fora da tradição anglo-saxônica. Na França, o país de Napoleão, por exemplo, com a notável exceção da obra de Raymond Aron (1980), quase não se encontram obras que considerem a guerra um objeto importante de estudo (Ruano-Borbalan, 2003). Para a visão das ciências sociais, a guerra parece não apenas algo pouco importante, mas um tema incompreensível (Berkowitz 2003). Embora eventualmente se possam compreender as causas que conduzem à guerra, ela não se apresenta, para as ciências sociais, como um fenômeno unitário surgido de necessidade históricas e/ou de possibilidade de ação 
racional por parte dos Estados. Se o Estado não é entendido como um ator político central do desenvolvimento histórico, senão ao contrário, como um epifenômeno do social, não pode estranhar a ausência do tema da guerra nas principais vertentes das ciências sociais. Nem a reflexão marxiana sobre a economia ou a weberiana sobre ação social (para não citar senão os dois clássicos mais representativos do campo das ciências sociais) permitiria os cientistas sociais chegarem até o Estado de uma forma não derivada. Isto cria um interessante qüiproquó para a maioria dos analistas sociais quando defrontados com a guerra, na medida em que esta, um ato magno do exercício de soberania dos Estados, não consegue ser pensada por eles, apesar de sua reivindicação explícita do princípio de soberania. O movimento pacifista cobrou novas forças com a ameaça da guerra nuclear e foi também utilizado como ferramenta de expansão do império soviético, conseguindo convencer muitos analistas de que a guerra já não era mais possível. Isto levou, de fato, não apenas a negar a guerra, mas também a não admitir de pensar o fenômeno da guerra.

Em resumo, ante os olhos dos cientistas sociais, as guerras são provas da perversão do sistema social antes do que qualquer outra coisa. Ainda que por caminhos opostos, existe também uma longa tradição metafísica do pensamento ocidental que deriva a guerra da natureza humana. De Platão a Freud, encontramos muitos autores que atribuem às paixões as causas das guerras. Seja como um resultado da "irracionalidade" humana ou social, o certo é que a guerra se apresenta para as principais vertentes do pensamento ocidental contemporâneo como algo irracional e dispensável, como conflitos que, independentemente de sua origem, produzem conseqüências anticivilizatórias. Assim, os cidadãos ocidentais do século XXI se confrontam hoje com o paradoxo de que a guerra se lhes apresenta como um fenômeno de primeira magnitude, porém explicado por teorias e disciplinas que recomendam (normativamente) que o sistema político internacional deve procurar a paz e evitar a guerra por todos os meios. Embora não deva ser atribuído ao realismo o contrário (isto é, uma propensão a justificar a guerra), certamente parece razoável propiciar uma análise da guerra com menos preconceitos filosóficos ou religiosos. ${ }^{2}$

${ }^{2}$ Desenvolvemos esta problemática mais extensamente em outro artigo (VIOLA \& LEIS, 2001). 
Uma reflexão aprofundada do fenômeno da guerra permite entendêla como um ato pautado nas relações entre Estados num contexto onde estão presentes diferentes perspectivas histórico-civilizatórias, como também diferentes critérios de moral e de justiça, além de diferença de interesses conjunturais e de desenvolvimento militar e econômico, evitando, assim, o recurso à irracionalidade para explicar o fenômeno. Observemos que a consideração essencialmente antipacifista da análise da guerra como um fenômeno complexo que inclui desde a política até a dimensão moral vale tanto para um realista como Morgenthau (1970), como para um idealista como Walzer (1991). Uma vantagem forte do realismo em relação ao idealismo acerca de sua capacidade de análise da política internacional, reside precisamente em prestar atenção a uma grande diversidade de fatores empíricos situados em diferentes dimensões, não privilegiando excessivamente nenhum deles em função de percepções normativas da realidade.

Após a o fim da Segunda Guerra Mundial, a visão realista se impôs de forma dominante nos países anglo-saxões. Porém, o mesmo não aconteceu em outros países, especialmente nos países periféricos, que tradicionalmente definiram suas políticas externas guiadas por consideraçôes normativas e/ou ideológicas terceiro-mundistas e/ou anticapitalistas. Tal como já foi antecipado, o interessante a destacar aqui é que o realismo que marcava a política externa dos países anglosaxôes também impregnava de forma dominante o campo acadêmico. Do mesmo modo, nos países periféricos a tendência para o idealismo de suas políticas externas também era acompanhada pelas academias respectivas. Esta questão referente à sociologia do conhecimento não é uma digressão. Registrar as marcas do campo intelectual nos países da América Latina, por exemplo, se torna decisivo na hora de pensar a realidade internacional. Talvez a principal nota comparativa seja que nos países anglo-saxões os campos científico e político estão claramente definidos e separados. Não acontece o mesmo em nossos países, onde os homens de ciência e os políticos são, às vezes, as mesmas pessoas.

Em um momento onde emergem no jogo político fatores civilizatórios de longo prazo, as idiossincrasias e as culturas políticas dos diversos países se tornam essenciais para que seus cidadãos possam entender, ou não, os acontecimentos. Se os atentados de 11 de Setembro 
nos Estados Unidos e seus provados vínculos com as redes terroristas globais do fundamentalismo islâmico não foram ainda suficientes para que a maioria da população dos países ocidentais (para não falar da população dos países não ocidentais) acordasse do doce sono de uma política pensada a partir dos valores e categorias associados à vida na sociedade civil, isto é já em si mesmo um fato importante a ser levado em conta. ${ }^{3}$ Nossa hipótese é que o fim do comunismo soviético e, principalmente, os crescimentos exponenciais na década de 1990, dos processos de globalização da economia e dos meios de comunicação, produziram a miragem da substituição do protagonismo histórico dos Estados e dos mercados pelo da sociedade civil, desqualificando assim o papel dos Estados modernos e dos mercados como elementos civilizatórios (Zakaria, 2003). Esta societalização da política fez ela perder não apenas densidade ontológica, mas também sua tradicional perspectiva histórica. Em efeito, o espectro de teorias que universalizam às diversas manifestaçôes da sociedade civil (teorias que incluem desde os autores do multilateralismo até os do cosmopolitismo, como Giddens, Beck, Bauman, Habermas, etc.), não apenas fazem que a política perca importância frente a outras atividades humanas, mas também nos levam a esquecer o caráter eminentemente histórico desta atividade. Assim, a política perde tanto sua visibilidade no presente como em relação ao futuro. ${ }^{4}$

Resumindo, em seu sentido mais elevado, a política não é tanto o que os indivíduos fazem na dimensão atemporal da sociedade civil, mas o que os Estados fazem numa perspectiva histórica de contribuição ao desenvolvimento da humanidade. Portanto, com as novas guerras do século XXI (Afeganistão e Iraque), não está apenas em questão a interpretação desses fatos pontuais, mas também as condições para pensar a política. Retomando uma antiga metáfora de Marx, que reivindicou a inversão do pensamento hegeliano, trata-se hoje de colocar novamente Hegel sobre seus pés. Isto é, trata-se de abandonar a especulação metafísica da política que deriva o mundo das visões dos indivíduos, para retomar a análise empírica de um mundo apoiado nas

\footnotetext{
${ }^{3}$ Desenvolvemos este tema em nosso artigo. Mudanças na direção de uma globalização multidemensional complexa (VIOLA \& LEIS, 2003)

${ }^{4}$ Talvez por isso sejam os neoconservadores, com seu forte senso da história, aqueles que melhor reagem frente a este "apequenamento" da política.
} 
ações dos Estados, as quais, necessariamente, não são transparentes para a compreensão dos indivíduos. Ou melhor, as guerras do Afeganistão e do Iraque demandam um esforço conceitual para sua compreensão, precisamente porque elas estão fora do alcance e da compreensão da ampla maioria dos indivíduos, na medida em que estes "privatizaram" sua concepção da política e não conseguem se situar fora do restrito universo da sociedade civil. Que a história do mundo demande um esforço conceitual para ser interpretada não implica, obviamente, que não seja feita pelos seres humanos, senão que estes realizam mais ou menos o que pretendem, mas também um excedente do qual não tem consciência nem se propunham realizar (D’Hondt, 1971). Esse excedente é inevitável porque a política (entendida aqui, na sua máxima expressão, como ação histórica) é feita à escala individual e supra-individual, simultaneamente. De acordo com Hegel, esse excedente define a chamada "astúcia da razão". Em outras palavras, o lado proposital da ação humana aponta ao interesse particular e/ou imediato, enquanto o "imprevisível” excedente a uma construção de longo prazo.

Aristóteles (1958) deixou pairando no ar algumas questôes que têm recebido variadas respostas ao longo da história. Ele se perguntava se eram idênticos o homem bom e o bom cidadão e, indo mais longe, se perguntava se era possível ser um homem bom, ainda quando este não pudesse ser um bom cidadão (por estar vivendo num estado corrupto ou perverso). Na Filosofia do Direito, Hegel (1975) estabeleceu uma oposição fundamental que ajuda a despejar muitas das confusões modernas associadas à antiga questão aristotélica. Hegel distingue a moralidade subjetiva (moralität) de moralidade objetiva (sittlichkeit). A primeira é uma referência direta à concepção kantiana da moral, onde a ação moral se define por um critério formal e abstrato (a validade universal da intenção que orienta a ação). A moralidade objetiva, pelo contrário, não se estabelece em relação a uma norma abstrata, mas na integração consciente do homem à família, à sociedade civil e, sobretudo, ao Estado. O critério de universalidade deixa assim de ser abstrato, conforme Kant, para ser concreto. Portanto, não é a carga utópica ou ética das ações, independentemente das instituiçóes existentes, o que define o caráter positivo e o negativo das mesmas. Sem um Estado bom é impossível praticar boas ações no plano da política. 
$\mathrm{Na}$ dimensão das relações internacionais a argumentação hegeliana sobre a moral se dissolve, dada à ausência de um Estado supranacional. $\mathrm{O}$ juízo moral não se aplica à política internacional porque todos os Estados, independente do seu tamanho, população, riqueza, poder militar, são iguais em direito e não aceitam a existência de qualquer poder supranacional que possa impor-lhes regras e sanções. Em conseqüência, se os Estados têm a liberdade de agir da maneira que melhor entender, a política internacional nos remete forçosamente para a análise da "qualidade" de cada um dos Estados ou, em outras palavras, para a perspectiva histórica dos valores colocados em jogo pelo arcabouço institucional desses Estados. Do ponto de vista hegeliano não pode haver qualquer dúvida de que os progressos da humanidade se realizam por meio de guerras e revoluções. Na Introdução da Filosofia da Historia, Hegel deixa perfeitamente claro que os períodos pacíficos não são períodos históricos propriamente ditos (Hegel, 1955). Assim, a história universal é um processo que vai do despotismo oriental até o estado moderno, na qual se produzem progressos históricos sempre que os homens avançam na consciência do valor essencial da liberdade para a vida política. Não podemos cair em simplificações na hora de avaliar uma guerra colocada no contexto de um conflito civilizatório sustentado por Estados com diferenças substanciais em relação à liberdade.

No mundo pós-11 de Setembro, temos algo mais que o comentado choque de civilizaçôes de Huntington (1997). As recomendações de Huntington apontavam para a preservação dos núcleos irredutíveis de cada civilização. Ainda que falando de uma perspectiva realista, sua recomendação se inscreve dentro dos limites do pensamento da modernidade para compreender a fundo a perspectiva histórica da ação política dos Estados. Se isto acontece com um autor como Huntington, que não dizer daqueles que tentam pensar o mundo pós-11 de Setembro a partir das teorias do multilateralismo e/ou do cosmopolitismo. ${ }^{5}$ Por trás deste tipo de propostas se encontra a pretensão iluminista de priorizar a

\footnotetext{
${ }^{5}$ A modo de exemplo, ver as análises de: Bauman, 2002; Beck, 2002; Habermas, 1999; e Held, 2002. No plano nacional, as limitaçôes para pensar a política internacional pós-11 de Setembro, podem ser observadas nas análises de autores como Luciano Martins, Luiz Carlos Bresser-Pereira e Guido F. Silva Soares, publicadas no dossiê Estados Unidos e a ordem mundial, na revista Política Externa, vol. 12, n. 1, jun-ago 2003.
} 
legalidade internacional por cima das necessidades históricas quando estas implicam conflitos potenciais. Em outras palavras, essas propostas levam a congelar a realidade por meio da relativização dos valores em jogo e da aceitação da ação dos Estados apenas de forma defensiva e secundária, reduzindo, de um modo ou de outro, os problemas políticos (inclusive os conflitos internacionais) a problemas sociais. ${ }^{6}$ Não é por acaso que por trás do unilateralismo posto em prática pelas intervenções no Afeganistão e no Iraque não se encontrem grandes teorias sociais (nem teóricos). Para o bem ou para o mal, o que se combinou em chamar "unilateralismo americano" reflete a tentativa de determinados atores ocidentais (sejam de esquerda ou de direita, já que os governos Bush e Blair não possuem o mesmo background ideológico) de devolver-lhe à política sua antiga hierarquia. Pensar que a economia capitalista mundial poderia levar os valores ocidentais para o centro do cenário é uma falsa visão da história (que hoje se cultiva tanto na esquerda como na direita). A política praticamente se evaporaria e o despotismo e a decadência tomariam conta de um mundo cujos principais atores não hierarquizassem os valores centrais da tradição ocidental. As decisões dos governos Bush e Blair geram um forte excedente (no sentido hegeliano acima comentado), sobre o qual seria prematuro se aventurar a julgá-los de forma definitiva e conclusiva. Mas o atual vazio teórico (ou melhor, de comentários positivos por parte dos teóricos de nossa época) em torno deste unilateralismo deve ser considerado como normal, na medida em que ele contradiz profundamente o senso comum. $\mathrm{Na}$ verdade, o grande acontecimento histórico de nossa época não deriva da ação do terrorismo islâmico que derrubou as torres gêmeas de Nova York, mas da firme decisão dos governos dos Estados Unidos e de outros Estados aliados de combatê-lo sem trégua em todas suas manifestações. É portanto nas intervenções militares no Afeganistão e no Iraque que se encontram referências aos pressupostos racionais da ação histórica e não na série de atentados terroristas que vêm sacudindo o mundo a partir do 11 de Setembro de 2001. A rigor, as ações históricas civilizatórias tiveram fortes precedentes ao longo do século XX.

\footnotetext{
${ }^{6}$ Um exemplo disso foi dado recentemente pelo presidente Luiz Inácio Lula da Silva, na conferência Combatendo o terrorismo em prol da humanidade (Nova York, 22.9.2003), onde conclui sua intervenção afirmando que o terrorismo era basicamente um "sintoma de mal-estar social". Disponível em: <http://www.mre.gov.br/>.
} 


\section{Reformas liberais como fundamento da ordem unipolar}

A democracia política e a economia de mercado, enquanto mecanismos de libertação dos indivíduos e de maximização dos potenciais de uma sociedade qualquer, tornaram-se preponderantes no mundo anglo-saxônico antes que em qualquer outra parte do mundo. Desde a sua entrada na Segunda Guerra Mundial, os Estados Unidos se constituíram na principal força promotora da expansão desses valores, primeiro sendo a força decisiva na destruição militar do fascismo europeu e do totalitarismo imperial japonês e, depois, promovendo a reconstrução dos países da Europa Ocidental e do Japão na forma de um capitalismo democrático. É evidente que esta reconstrução não tratou de reproduzir valores econômicos e políticos liberais radicais na forma como hoje se convencionou chamar de neoliberalismo, ou seja, estado mínimo e mercado regulado com o propósito de maximizar a liberdade econômica e a concorrência interna e externa. Neste momento, os Estados Unidos eram eles próprios penetrados por uma visão mais coletivista do capitalismo - a Revolução keynesiana e suas derivações microeconômicas - e mesmo da democracia, com uma ênfase crescente no estabelecimento de instrumentos de consulta neocorporativista. ${ }^{7}$

O ímpeto norte-americano de construir um mundo capitalista e democrático esteve limitado às regiōes em que os Estados Unidos consideravam estratégicas do ponto de vista geopolítico. Neste sentido, a política dos Estados Unidos em relação à países que faziam parte de sua área de influência direta e segura, especialmente a América Latina, obedeceu a uma lógica mais imediatista, inclusive favorecendo a constituição e a manutenção de regimes claramente autoritários e de um modelo econômico não-liberal (Viola \& Pio, 2003). A promoção da democracia no plano mundial voltou a ser forte na definição da política externa norte-americana nas administrações de Jimmy Carter (19771981) e de Ronald Reagan (1981-1989). No primeiro caso, a democracia era defendida no âmbito de uma nova visão quanto às alianças estratégicas dos EUA - fim da aliança com regimes autoritários anticomunistas e a

\footnotetext{
7 Trata-se de uma referência ao modelo conhecido como "corporativismo societal", no qual o Estado compartilha o poder político com representantes de empresários e sindicatos, a fim de dar maior efetividade às decisões públicas.
} 
promoção de movimentos de defesa dos direitos humanos no mundo comunista, dos quais a luta do movimento polonês Solidariedade é o caso mais exemplar.

Com Reagan, a defesa da democracia tomou a forma da revitalização da economia de mercado no Ocidente, a começar pelos Estados Unidos e a Grã-Bretanha - luta contra os excessos estatistas e coletivistas do pósguerra - e confronto militar com a União Soviética (Yergin \& Stanislaw, 1998). Estes movimentos da administração Reagan são fundamentais para explicar tanto a derrocada política e econômica dos países que compunham o bloco soviético (1985-1989), quanto à emergência de um processo de reforma estrutural do modelo de economia planificada na China. Nas administraçóes Carter e Reagan, apesar da ênfase na adoção da democracia, esta não se aplica a todos os países e regiōes. A queda do bloco soviético, no final da década de 1980, legitima a ênfase que vinha sendo dada pelos governos de Reagan e de Thatcher na necessidade de reformar estruturalmente o capitalismo ocidental. A reforma "neoliberal", iniciada na Inglaterra e nos Estados Unidos na primeira metade dos anos 80, propunha-se a reduzir o papel do Estado na economia e a aumentar da interdependência econômica no plano internacional. ${ }^{8}$

A expansão do modelo neoliberal tanto aos países do centro do sistema - França, Espanha, Itália - quanto aos da periferia - América Latina - sofreu a interferência de pelo menos três fatores importantes. Primeiro, por se tratar de um modelo em construção, ou seja, que não havia clareza quanto ao timing e à seqüência das medidas que visavam revitalizar o sistema, ele tinha efeitos negativos a curto prazo - derivados da baixa competitividade das empresas que antes atuavam em sistemas autárquicos e pouco concorrenciais, a trabalhadores muito protegidos por legislaçóes paternalistas e que desestimulavam a capacitação constante. Segundo, a falta de um passado nitidamente liberal criava um déficit institucional que posteriormente se mostrou fundamental para o sucesso das reformas, especialmente no que diz respeito às capacidades do Estado para gerenciar a transferência de ativos para o setor privado, a abertura

\footnotetext{
${ }^{8}$ Em nossa visão, o significado dos governos de Reagan e Thatcher é, em geral, muito pouco estudado e compreendido na América Latina. Uma obra seminal que insere as reformas de Reagan e Thatcher na batalha geral entre Estado e mercado no século XX é YERGIN, Daniel \& STANISLAW, Joseph. The commanding heights: the battle for the world economy, 1998.
} 
do mercado às importações, a criação de políticas (sociais, de estímulo à modernização e de incentivo à inovação) que atendessem às necessidades dos grupos prejudicados no curto prazo. Por fim, as resistências políticas surgidas nesses países proviam fundamentalmente de dois pólos: de um lado, os grupos ameaçados pelas mudanças propostas (empresários e trabalhadores nos setores menos eficientes, funcionários públicos, e outros beneficiários das políticas do estado intervencionista); de outro, ideologias coletivistas, fortemente enraizadas nessas sociedades e que privilegiam a igualdade em detrimento da prosperidade.

$\mathrm{O}$ resultado das transformações da ordem política e econômica internacional nas últimas duas décadas pode ser expresso na unipolaridade estrutural do mundo contemporâneo, em torno dos valores e instituiçóes do capitalismo democrático anglo-saxônico, especialmente o norteamericano. Esta unipolaridade do mundo real se fundamenta na concentração, nos Estados Unidos, de aproximadamente 30\% do PIB, $45 \%$ dos gastos militares, $60 \%$ das patentes mundiais e a maior atratividade sobre imigrantes empreendedores (aproximadamente um milhão por ano na última década) de todo o mundo (Kissinger, 2001; Brooks \& Wolforth, 2002; Nye, 2002).

A unipolaridade estrutural coloca uma série de questionamentos sobre em que medida as instituições internacionais contemporâneas se mostram adequadas:

(a) A hegemonia norte-americana não se expressa no formato institucional da ONU, cujo Conselho de Segurança assegura direito igual de veto à cinco potências, refletindo, assim, muito mais a distribuição de poder resultante da Segunda Guerra Mundial do que aquela que caracteriza o mundo pós-1989 (Buzan, 2002).

(b) São frágeis os movimentos que têm como propósito contrabalançar a unipolaridade norte-americana na medida em que as diversas potências secundárias - os demais membros do Conselho de Segurança (Reino Unido, França, Rússia e China) e do G-7 (Alemanha, Japão, Itália e Canadá) -, que precisariam unir-se para equilibrar o poder norte-americano, têm menos interesses comuns entre si do que com os Estados Unidos (Kissinger, 2001; Nye, 2002).

(c) A economia de mercado, em moldes muito semelhantes àqueles defendidos por Reagan e Thatcher, mostra-se fundamental para o sucesso 
econômico, como atesta a forte correlação entre a realização de taxas altas e sustentáveis de crescimento econômico e a adoção prévia de reformas pró-mercado nos últimos vinte anos, porém uma parte muito importante da população do mundo (nos países pobres e emergentes) continua desconhecendo ou rejeitando a economia de mercado.

(d) A emergência de novas ameaças à segurança internacional derivadas da proliferação de armas de destruição em massa, especialmente em regimes que fundamentam sua legitimidade (e atenuam seu fracasso econômico) em sua capacidade de desafiar os Estados Unidos e do crescimento e da globalização de redes terroristas originadas no radicalismo islâmico xiita e sunita não encontra formulação definida dentro do sistema ONU

(e) Os atentados terroristas de 11 de Setembro de 2001 mudaram definitivamente a percepção das elites norte-americanas sobre o mundo, o papel e os interesses nacionais dos Estados Unidos, levando à prevalência de uma visão de política externa assentada na lógica do confronto total em relação ao totalitarismo islâmico e aos regimes proliferadores, independentemente de qualquer reconhecimento por parte das instituições internacionais, gerando uma defasagem entre o plano legal e o plano do poder criando condições propícias para o crescimento do antiamericanismo (Kagan, 2002; Hoffman, 2002).

(f) Existem, dentro do mundo democrático, duas visões a respeito de como lidar com a radicalização dos inimigos da democracia: uma negociadora e outra de confronto. Neste sentido, as posições de George W. Bush e Tony Blair, no início do século XXI, são herdeiras das de W. Churchill, F.D. Roosevelt, Reagan e Thatcher; e, as visões de Chirac e Schroeder são herdeiras das posições de Chamberlain, Nixon, Carter e Clinton (Mandelbaum, 2002; Kagan, 2003).

Não deve restar dúvidas de que o 11 de Setembro significou para os Estados Unidos uma ruptura radical em relação a como este país se coloca no mundo. Os ataques são interpretados indiscutivelmente como um ato de guerra, o qual invoca uma resposta de guerra. Os atentados transformam os Estados Unidos de uma "superpotência vitoriosa" para uma "superpotência sob ataque" e uma "superpotência ameaçada". Uma parte significativa da população e das elites de vários países tem dificuldade para compreender os termos em que se deu esta ruptura, a 
resposta norte-americana e mesmo a interpretação como essas dinâmicas afetam o interesse nacional de seus próprios países.

Os ataques terroristas foram deferidos aos centros de poder econômico, militar e cultural dos Estados Unidos. Seu propósito essencial, portanto, era destruir o sistema norte-americano - sua prosperidade, seus valores e seus símbolos mais fundamentais. Tony Blair, primeiro-ministro britânico, foi um dos primeiros líderes a reconhecer que os ataques de 11 de Setembro alvejavam o Ocidente, representado pelos valores e instituiçóes que fizeram dos Estados Unidos o centro desta civilização. A repetição do sentimento de ser atacado em seu próprio território injustificadamente - invocando o ocorrido em Pearl Harbor, quase cinqüenta anos antes - transformou, radicalmente, o mind set americano. A destruição do terrorismo e dos regimes que lhe dão guarida ou com eles convivem se torna a única resposta consistente com o padrão histórico dos Estados Unidos. A grande maioria da opinião pública e das elites internacionais se mostrou incapaz de entender que, em se tratando da potência hegemônica, os termos da resposta não estariam submetidos a discussões e deliberações multilaterais. A superpotência, agora ameaçada, se vê diante da necessidade de agir com vistas a se recolocar como vitoriosa e isso se traduz nas doutrinas da supremacia militar incontestável e do ataque preventivo. As vacilações e tolerâncias de vários fóruns multilaterais ao longo da década de 1990 para com países vistos como transgressores das regras de convivência pacífica (regimes proliferadores de armas de destruição em massa e santuários do terrorismo e do crime organizado) haviam reforçado as dúvidas históricas do povo americano com relação à eficácia das Nações Unidas. O que grande parte da opinião pública mundial parece ter dificuldade de entender é que os Estados Unidos só confiam em si mesmos para realizar a tarefa de garantir sua segurança (Friedman, 2002). Em razão disso, parece ter chegado definitivamente ao fim o ciclo da ambivalência em relação a unipolaridade (1989-2001). A potência hegemônica decidiu assumir a unipolaridade. A partir do 11 de Setembro, profundas diferenças em termos de quanto cada país se adaptará à nova realidade da segurança internacional resultarão da capacidade de cada um para percebê-la e a ela reagir de forma pragmática. Em vez de caminhar na direção da multipolaridade, como imaginavam muitos formuladores da política externa em países como a França e o Brasil, o mundo aprofunda sua característica unipolar. 
As intervenções humanitárias (Bósnia 1995-2003, Somália 19921993, Kosovo 1999-2003) e de substituição de regimes ditatoriais (Haiti 1994, Afeganistão 2001-2003) na política internacional tem sido objeto de muitas controvérsias acadêmicas durante toda a última década. Esse debate se torna especialmente complexo em função da inversão da política produzida na mentalidade contemporânea, tal como fora argumentado anteriormente, por um lado, da contaminação com as ações do terrorismo global e da proliferação de armas de destruição em massa de um crescente numero de rogue states, por outro. Existe certamente um enorme consenso detrás da demanda de governabilidade global, porém esta demanda é realizada por atores que se entrincheiram nos direitos do princípio da soberania nacional e esquecem as obrigaçóes. Num mundo repleto de "vozes" soberanas, mas onde praticamente um país (Estados Unidos) tem a capacidade e a vontade (e, portanto, a responsabilidade) para intervir militar e politicamente em função da preservação e desenvolvimento da governabilidade global se gera um conflito labiríntico entre normas internacionais e os jogos de interesses dos estados nacionais.

\section{As diferenciações na elite americana e seu impacto sobre a governabilidade global: o arco de variação entre unilateralismo e multilateralismo}

A luta contra o terrorismo põe um dilema entre a perda de governabilidade do sistema mundial, acompanhada do respeito à legalidade internacional vigente por parte dos Estados, versus o aumento da governabilidade global, mas acompanhada de intervenções militares por parte dos EUA e seus aliados fora da legalidade vigente. Nossa hipótese, neste ensaio, é que o atual momento histórico implica o desenvolvimento de uma guerra de novo tipo contra o terrorismo e os rogue states (com capacidade de possuir armas de destruição massiva) que certamente impede harmonizar a política internacional com o direito internacional vigente. Mas este exercício de unilateralismo, principalmente por parte dos Estados Unidos, vai muito além da guerra contra o terrorismo, contribuindo para redefinir de forma mais realista e racional os atuais parâmetros da governabilidade global. Neste sentido, utilizando a metáfora hegeliana, a guerra contra o terrorismo pode ser interpretada 
como a astúcia da razão. Não foram os ataques ao World Trade Center, nem as invasões do Afeganistão e do Iraque que geraram o impasse da diplomacia pacifista ou do papel da ONU no mundo, por exemplo. Há muito tempo (muito antes do 11 de Setembro de 2001!) que as instituiçóes que regulam a ordem da política e da segurança internacional estão obsoletas (Glennon, 2003). Não é um fato recente que a Assembléia Geral e o Conselho de Segurança da ONU não podem ser considerados como base da ordem mundial, em um mundo onde os estados de direito historicamente vêm crescendo em progressão aritmética e as tiranias e as cleptocracias em progressão geométrica (Chua, 2003; Rotberg, 2002). Diferentemente, as instituições de Bretton Woods são bastante realistas por estarem fundadas no diferencial de riqueza entre os Estados.

Destes fatos resultam algumas observações relevantes em relação ao atual unilateralismo dos Estados Unidos na política internacional. A primeira é que esse unilateralismo não é resultado apenas de uma resposta dos Estados Unidos ao terrorismo, mas fruto também de necessidades históricas produzidas por uma desordem mundial que precede em muito aos atentados de 11 de Setembro de 2001 (Cohen, 2001; Hoffmann, 2002). Neste sentido, uma segunda observação a fazer é que as intervençōes humanitárias do período pós-Guerra Fria (Bósnia 1995-2003, Somália 1992-1993, Kosovo 1999-2003) já apresentavam um grau crescente de desconhecimento da autoridade do Conselho de Segurança da ONU (sendo Kosovo o melhor exemplo). Como se podem observar, as ações dos Estados Unidos inspiram sempre numerosas críticas, ainda quando não resultam em genocídios, direta ou indiretamente. Por isso resulta pouco menos que um escândalo que, quando a ONU aparece associada por omissão a um genocídio, sejam escassas as vozes que se levantam para criticar. Um dos exemplos, relativamente recente, mais notáveis da incapacidade da ONU para evitar um genocídio talvez seja o caso de Ruanda, na metade dos anos 90. Vale a pena mencionar que neste caso, um conflito baseado no enfrentamento histórico das etnias Hutus e Tutsis (intimamente associado ao comportamento passado e presente dos países europeus com presença na área - especialmente Bélgica e França), em poucos meses levou a morte, aproximadamente, um milhão de pessoas não beligerantes. Embora a literatura classifique o caso de Ruanda como uma intervenção humanitária autorizada, o 
papel da ONU foi claramente negativo, já que as demoras e rodeios do Conselho de Segurança para autorizar uma intervenção armada foram um grande facilitador do genocídio. Quando finalmente a ONU autorizou e a França decidiu intervir, já não havia nada mais a fazer, visto que a tragédia estava consumada (Rodrigues, 2000). As vítimas dessa horrível tragédia teriam preferido seguirem vivas, ainda que para isso fosse necessária uma intervenção unilateral na contramão dos protocolos da ONU.

Sendo possível estabelecer certa continuidade entre o "unilateralismo" da Otan em Kosovo e o unilateralismo anglo-americano no Iraque, por exemplo, isto quer dizer que não estamos assistindo a uma política de "um" governo americano, em particular (seja Clinton ou Bush), mas a política de um Estado frente as necessidades históricas de longo prazo (Bacevich, 2002). Uma última observação que se pode extrair dos acontecimentos do presente (sobretudo levando em conta os esforços de nation-building numa perspectiva democrática de países como Kosovo e Iraque) é que esse unilateralismo responde a necessidade de construir uma governabilidade global associada tanto à defesa dos direitos humanos como à segurança internacional.

Contudo, apesar dessa continuidade, é claro que existem diferenças significativas dentro da elite americana com relação a como lidar com os problemas da ordem mundial pós-11 de Setembro, e essas diferenças se projetam em graus variáveis de intensidade e proporcionalidade sobre quase todas as democracias ocidentais. Analisando o quadro de posiçôes sobre política externa dentro da elite americana em setembro de 2003, podemos diferenciar quatro correntes ou grupos mais relevantes: os unilateralistas, os unilateralistas-moderados, os multilateralistasmoderados e os multilateralistas. Esta classificação dos grupos dentro da elite americana é de nossa elaboração e não pretende ter um valor teórico significativo, mas sim procura auxiliar na compreensão do complexo fenômeno das elites de política externa e de defesa americana.

Os unilateralistas ou neoconservadores ocupam uma posição central no governo Bush: o vice-presidente Dick Cheney, o ministro de Defesa Donald Rumsfeld, a assessora de Segurança Nacional Condolezza Rice, o vice-ministro de Defesa Paul Wolfowitz e o subsecretário para Controle de Armamentos Bolton. Este grupo surgiu no fim da década de 1970 e ganhou rapidamente muito prestigio perante Reagan e o grupo do 
Partido Republicano crítico de Nixon e Kissinger. Para os unilateralistas, o totalitarismo islâmico no início do século XXI é uma ameaça aos Estados Unidos e às democracias de mercado comparável ao totalitarismo comunista durante a Guerra Fria. Inspirados pela política de confronto com o comunismo soviético levada adiante com sucesso por Reagan, preconizam uma política de confronto total com o totalitarismo islâmico que se traduz na fórmula de ataques preventivos e promoção, em graus variáveis, da democratização do mundo islâmico. Para este grupo, as superioridades econômica e militar americanas devem traduzir-se em uma política externa agressiva, na qual as decisões americanas não seriam limitadas pela necessidade de chegar a um consenso com os aliados. Para este grupo, as alianças formais e estáveis como a Otan, passam a ser secundárias, sendo substituídos pelas alianças ad hoc, tomando-se por base as necessidades definidas pelos Estados Unidos por meio da fórmula: não é a aliança que define a estratégia, mas sim a estratégia que define a aliança (coalition of the willing) (Bush, 2002; Ullman, 2002; Pollak, 2003). É interessante notar que depois de um longo ciclo de separação, Kissinger convergiu com este grupo a partir de 9 de Setembro. Dentre os intelectuais que não participam do governo Bush, destacam-se como membros deste grupo Bill Kristol e Robert Kagan (Kagan, 2002 e 2003). É interessante destacar que esta posição é minoritária na comunidade acadêmica de relaçóes internacionais americana.

Os unilateralistas-moderados ocupam uma posição importante no governo Bush, embora secundária em relação aos unilateralistas. Os principais expoentes desta corrente são o secretario de Estado Colin Powel e o diretor da CIA (até 2004) George Tenet e encontra seu principal núcleo no establishment diplomático americano que por treinamento profissional tende a ver o mundo com maior inclinação para a negociação. Para este grupo, que predominava no governo Bush antes de 11 de Setembro (neste período Condolezza Rice pertencia a este grupo), os atentados terroristas mudaram dramaticamente a arena internacional e por isso

\footnotetext{
${ }^{9}$ Bill Kristol foi o fundador da revista bimestral The Public Interest na década de 1970 e fundador da revista semanal The Weekly Standard nos anos 90. Este semanário é considerado o mais influente na Washington de Bush. Robert Kagan elaborou uma teoria sistêmica sobre as diferenças entre Estados Unidos e Europa que teve sua versão mais desenvolvida no influente e provocativo livro: Ofparadise and power.
} 
eles concordam com os unilateralistas na necessidade de uma política de confronto máximo com o totalitarismo islâmico. Porém, diferente do primeiro grupo, os unilateralistas-moderados pensam que é necessário desenvolver um trabalho de persuasão com os aliados tradicionais dos Estados Unidos de modo a conseguir o apoio da maioria deles, mesmo que isso implique na realização de certas concessões quanto ao perfil e ao timing da política de confronto. É importante destacar que este grupo procura o apoio dos principais aliados dos Estados Unidos (a coalizão de Kosovo) e não se fixa na aprovação do Conselho de Segurança da ONU como fundamento da legitimidade da política americana, além de propor uma ambiciosa estratégia de expansão da Otan e de redefinição de sua missão com escopo planetário (Glennon, 2003). Este grupo conta com dois pré-candidatos presidenciais do Partido Democrata: Joe Liberman e Wesley Clark. No Reino Unido, os unilateralistas moderados estão representados pela quase totalidade do Partido Conservador e pela fração de Blair no Partido Trabalhista. Dentro da comunidade acadêmica de relações internacionais, a grande maioria dos que aderem ao paradigma neo-realista simpatiza com este grupo, destacando-se Keneth Waltz e Zbigniew Brzezinski (Brzezinski, 1997). Kissinger pertencia a este grupo antes do 11 de Setembro (Kissinger, 2001).

Os multilateralistas moderados, que estavam no centro do poder no governo Clinton, mas se encontram fora do governo com Bush, embora ocupem algumas posiçóes de influência no Congresso. Para este grupo, a guerra contra o terrorismo islâmico deve ser limitada e não deve basear-se na doutrina do ataque preventivo. Este grupo propõe uma estratégia baseada numa combinação das seguintes políticas: resposta incisiva contra a Alqaeda como a realizada no Afeganistão, concentração na defesa do território americano, promoção intensiva do desenvolvimento de energias renováveis para se tornar independentes do petróleo islâmico, fortalecimento da Otan como centro da política de defesa americana com uma importância similar a que tinha na Guerra Fria, retomada de um papel ativo do governo americano para resolver o conflito israelense-palestino, e reconhecimento de um papel importante ao Conselho de Segurança da ONU. Este grupo somente teria apoiado o ataque ao Iraque desde que aprovado pelo menos pelos aliados ocidentais dos Estados Unidos e melhor ainda pelo Conselho de Segurança da 
ONU. Os candidatos presidenciais democratas, John Kerry e John Edwards situam-se neste grupo, que conta também com a presença de Bill Clinton e Al Gore. Os grandes formuladores doutrinários deste grupo são Madeleine Albright e Joseph Nye (Keohane \& Nye, 2001; Nye, 2002 e 2003; Mandelbaum, 2002; Prestowitz, 2003). No Reino Unido, os multilateralistas-moderados são representados pelo centro do Partido Trabalhista. Na comunidade de relaçôes internacionais este grupo conta com o apoio da maioria dos scholars que aderem ao paradigma neoliberal institucionalista.

Os multilateralistas ocupam uma posição marginal na elite americana atual. Para este grupo, a superioridade americana no mundo está agora no seu ápice e tende, necessariamente, a declinar devido à razões demográficas (crescimento da China e da Índia), econômicas (limitada poupança interna e consumismo da população americana) e culturais (o multiculturalismo está cada vez mais enraizado no mundo e erosiona a hegemonia dos valores americanos). ${ }^{10}$ Para este grupo, os Estados Unidos devem retirar-se de varias áreas do mundo e contribuirem para formação de um novo regime de segurança simultaneamente multipolar e multilateral. Este grupo é crítico da aliança especial dos Estados Unidos com Israel e propõe uma menor influencia das grandes corporações na política interna e externa americana. Entre os pré-candidatos democratas, Howard Dean, expressou este grupo, particularmente porque sua base foi construída com utilização intensiva da Internet pelos movimentos sociais históricos (direitos civis, pacifistas, ambientalistas, homossexuais e feministas). O candidato independente Ralph Nader também pertence a este grupo. Em virtude da estrutura de preferências políticas americanas, não existe nenhuma possibilidade dos multilateralistas se instalarem na Casa Branca em um futuro previsível. No Reino Unido, os multilateralistas contam com o apoio da esquerda trabalhista e do Partido Social-Democrata. Dentro da comunidade acadêmica de relações internacionais, este grupo tem o apoio de grande parte dos scholars que aderem aos paradigmas feminista e construtivista e autores que foram

\footnotetext{
${ }^{10}$ Embora longe politicamente deste grupo, a principal fundamentação para o multipolarismo na comunidade americana de relaçóes internacionais é dada por Samuel Huntington em The clash of civilization and the remaking of the world order e The Lonely Superpower.
} 
afastando-se do neoliberalismo institucionalista como James Rosenau (Rosenau, 2003).

Devido ao peso que teve a esquerda (comunista, socialista e socialdemocrata) na formação de quase todas as democracias ocidentais fora dos Estados Unidos (priorização dos valores igualdade/equidade sobre o valor liberdade), a visão dos unilateralistas e unilateralistas-moderados, ambos associadas à direita americana (priorização da liberdade sobre a equidade), têm limitada penetração fora dos Estados Unidos. Deste modo, produz-se um alinhamento político bastante diferente dentro das principais democracias no mundo pós-11 de Setembro, já que os grupos minoritários dentro da elite americana (multilateralistas-moderados e multilateralistas) são apoiados pelo coração das elites dos outros países (Lambert, 2003; Maravcsik, 2003). Isto não foi assim durante a primeira fase da Guerra Fria quando a doutrina de contenção do comunismo das elites americanas era apoiada pelo núcleo das elites européias. Contudo, a situação atual aproxima-se um tanto do quadro da primeira metade da década de 1980, quando a doutrina reaganiana de escalada confrontacional com a União Soviética era temida por parte importante das elites européias continentais.

Existe quase consenso nos estudos acadêmicos sobre política externa americana que, em geral, muda pouco com a mudança de presidente ou de partido no governo porque existe uma lógica de longo prazo do Estado americano que é mais profunda (Bacevich, 2002; Beasley, Kaarbo \& Sbarr, 2002; Brooks \& Wolfort, 2002). A principal mudança nos últimos anos na política externa americana não foi provocada pela volta ao poder dos republicanos em janeiro de 2001, senão por um atentado de repercussões sistêmicas (o 11 de Setembro), e a necessidade de resposta por parte do Estado americano. As mudanças processadas na política externa americana nos últimos dois anos são profundas e irreversíveis, indo além da reeleição ou não de Bush. A atual política externa americana é uma resultante intermediária entre os unilateralistas e os unilateralistas moderados, com predomínio dos primeiros em virtude dessa lógica profunda do Estado americano, e para além dos exageros dos discursos eleitorais, o intervalo de variação maior possível para os próximos anos é uma passagem à centralidade dos unilateralistas-moderados em aliança com os multilateralistas-moderados. Mesmo que esta nova geometria 
seja possível para 2005, ela não é a mais provável, sendo possível a continuidade da atual geometria ou um realinhamento que coloque no centro aos unilateralistas-moderados apoiados pelos unilateralistas.

\section{Conclusão}

Para concluir, a primeira década do século XXI está fortemente marcada por um unilateralismo associado a uma guerra de longa duração contra o radicalismo islâmico (e potencialmente outros radicalismos étnicos ou ideológicos) onde estão presentes fatores característicos das guerras passadas, mas também fatores novos associados a uma defesa de aspectos centrais da civilização ocidental. Em particular, o unilateralismo anglo-americano não pode ser separado da defesa da democracia liberal-representativa e do livre mercado, num contexto de aceleração da modernidade tecnológica. A experiência humana do último meio século mostra que o único caminho consistente para a prosperidade é o pleno desenvolvimento da liberdade. Não é a igualdade senão a liberdade (num contexto de igualdade jurídica) o fundamento da prosperidade. Porém, muitas sociedades nacionais fracassam na tentativa de construir uma economia de mercado devido ao excessivo peso de seu background coletivista e estatista. Em um mundo unipolar, é mais fácil construir ordem que gerar prosperidade. $\mathrm{O}$ unilateralismo anglo-americano cria condições gerais um pouco mais favoráveis, mas somente mudanças profundas nas culturas antiliberais poderão levar à prosperidade por meio da construção de democracias de mercado e do estado de direito.

Agosto de 2004

\section{Referências Bibliográficas}

ARISTOTELES. Politics. Tradução de Ernest Barker. Londres: Oxford University Press, 1958.

ARON, Raymond. Paz e guerra entre as naçôes. Brasília: Editora da UnB, 1980.

BACEVICH, Andrew Bacevich. American Empire. The Realities and Consequences of U.S. Diplomacy. Harvard University Press, 2002. 
BEASLEY, R. J. Kaarbo, J. Lantis \& M. Sbarr (orgs.). Foreign policy in comparative perspective. Domestic and international influences in state behavior. Washington: CQ Press, 2002.

BAUMAN, Zygmunt. Reconnaissance wars of the planetary frontierland. Theory, Culture \& Society. Vol. 19, n. 4, p. 81-90. 2002.

BECK, Ulrich. The terrorist threat - World Risk Society Revisited. Theory, Culture \& Society. Vol. 19, n. 4, p. 39-55. 2002.

BERKOWITZ, Bruce. The new face of war. Nova York: Free Press, 2003.

BOUDON, Raymond. O justo e o verdadeiro: estudos sobre a objectividade dos valores e do conhecimento. Lisboa: Instituto Piaget, 1998.

BRESSER-PEREIRA, Luiz Carlos. O gigante fora do tempo: a guerra do Iraque e o sistema global. Política Externa. Vol. 12, n. 1, jun-ago, 2003.

BROOKS, Stephen \& William Wolforth. American primacy in perspective. Foreign Affairs. Vol. 81, N. 4, Jul-Aug, 2002.

BRZEZINSKI, Zbigniew. The grand chessboard. American primacy and its geostrategic imperatives. Nova York: Basic Books, 1997.

BURKE, Peter. Uma História Social do Conhecimento. Rio de Janeiro: Jorge Zahar Editor, 2003.

BUSH, George W. National security strategy. The New York Times. 20 set 2002.

BUZAN, Barry. The security dynamics of a $1+4$ world. London School of Economics: 2002.

CAMPBELL, K. \& M. Flournoy. To prevail. An American strategy for the campaign against terrorism. Washington: Center for Strategic and International Studies, 2002.

CHUA, Amy. World on Fire. Nova York: Doubleday, 2003.

COHEN, Eliot. Defending America in the twenty-first century. Foreign Affairs. Nov-dec, 2000.

FRIEDMAN, George. The unipolar world. Austin: Stratfor, 2002. The War on Terror after Irak. Austin: Stratfor, 2003.

GLENNON, Michael. Why the security council failed? Foreign Affairs. Vol 82, n. 3, May-June, 2003. 
HABERMAS, Jurgen. Bestiality and humanity: a war on the border between legacy and morality. Constellations. Vol. 6, n. 3, p. 263-272. 1999.

HEGEL, Georg Wilhelm Friedrich. Lecciones sobre la Filosofia de la Historia Universal (vol. 1). Tradução José Gaos. Madri: Revista de Occidente, 1953. . Principios de la Filosofia del Derecho. Tradução de Juan Luis Vermal. Buenos Aires: Sudamericana, 1975.

HELD, David. Violence, law and justice in a global age. Constellations. Vol. 9, n. 1, p. 74-88. 2002

HOFFMANN, Stanley. Clash of globalizations. Foreign Affairs. Vol. 81, n. 4, July-August, 2002.

HUNTINGTON, Samuel. The clash of civilizations and the remaking of the world order. Nova York: Simon and Schuster, 1997.

. The lonely superpower. Foreign Affairs. Vol. 78, n. 2, Mar-April, 1999.

KANT, Inmanuel. El conflicto de las facultades. Buenos Aires: Editorial Losada, 1963.

KAGAN, Robert. Power and Weakness. Policy Review. N. 113, Jun 2002.

. Of paradise and power. America and Europe in the new world order. Nova York: Alfred Knopf, 2003.

KEOHANE, Robert \& Joseph Nye. Power and Interdependence. Nova York: Longman, 2001.

KISSINGER, Henry. Does America need a foreign policy? Toward a diplomacy for the $21^{\text {st }}$ century. Nova York: Simon \& Schuster, 2001.

LAMBERT, Richard. Missunderstanding each other. Foreign Affairs. Vol. 82, n. 2, Mar-Apr, 2003.

LUTTWAK, Edward. Turbo-capitalism.winners and losers in the global economy. Nova York: HarperColins, 1999.

MANDELBAUM, Michael. The inadequacy of American power. Foreign Affairs. Vol 81, n. 5, Sep-Oct, 2002.

MARAVCSIK, Andrew. Striking a new transatlantic bargain. Foreign Affairs. Vol 82, n. 4, Jul-Aug, 2003.

MARTINS, Luciano. O fundamentalismo de Bush e a ordem mundial. Politica Externa. Vol. 12, n. 1, jun-ago, 2003.

MARX, Carlos. Obras escogidas (vol. 1). Madri: Editorial Fundamentos, 1977. 
MORGENTHAU, Hans. Politics among nations. Nova York: Knopf, 1978.

NYE, Joseph. The paradox of American power. Why the world's only superpower can't go alone. Oxford University Press, 2002.

Aug, 2003.

. U.S. Power and strategy after Irak. Foreign Affairs. Vol 82, n. 4, Jul-

POLLAK, Kenneth. Securing the Gulf. Foreign Affairs. Vol 82, n. 4, Jul-Aug, 2003.

PRESTOWITZ, Clyde. Rogue nation. American unilateralism and the failure of good intentions. Nova York: Basic Books, 2003.

RUANO-BORBALAN, Jean-Claude. Pourquoi les guerres?. Sciences Humaines. N. 138, p. 16-22. 2003.

RODRIGUES, Simone Martins. Segurança internacional e direitos humanos: a prática da intervenção humanitária na pós-Guerra Fria. Rio de Janeiro: Renovar, 2000.

ROSENAU, James Rosenau. Distant proximities. Dynamics beyond globalization. Princeton University Press, 2003.

ROTBERG, Robert. Failed States in a world of terror. Foreign Affairs. Vol 81, n. 5. 2002.

SOARES, Guido F. Silva. Legitimidade de uma guerra preventiva em pleno 2003? Politica Externa. Vol. 12, n. 1, jun-ago. 2003.

STRAUSS, Leo. Natural right and History. Chicago: University of Chicago Press, 1953.

ULMAN, Harlan. Unfinished business. Nova York: Kensington, 2002.

VIOLA, Eduardo \& Héctor Leis. Dilemas civilizatorios da globalização frente ao terrorismo fundamentalista. Cena Internacional. Vol. 3, n. 2, dez 2001.

VIOLA, Eduardo \& Héctor Leis. Mudanças na direção de uma globalização multidimensional Complexa. In: LEIS, Héctor \& FARIA, Caleb (orgs.) Condição humana e modernidade no Cone Sul. Florianópolis: Cidade Futura, 2003.

VIOLA, Eduardo \& PIO, Carlos. Doutrinarismo e Realismo na percepção do interesse nacional: política macroeconômica, segurança e Alca na relação Brasil-Estados Unidos. Cena Internacional. Vol. 5, n. 1, jun, 2003.

VOEGELIN, Eric. Anamnesis. Notre Dame: University of Notre Dame Press, 1978.

WALZER, Michel. Just and unjust wars. Londres: Harper, 1991. 
YERGIN, Daniel \& STANISLAW, Joseph. The commanding heights. The battle between government and marketplace that is remaking the modern world. Nova York: Simon \& Schuster, 1998.

ZAKARIA, Fareed. The future of freedom. Liberal Democracy at home and abroad. Nova York: Norton, 2003.

\section{Resumo}

As intervenções humanitárias (Bósnia 1995-2003, Somália 1992-1993, Kosovo 1999-2003) e de substituiç̧ão de regimes ditatoriais (Haiti 1994, Afeganistão 2001-2003, Iraque 2003) na política internacional têm sido objeto de muitas controvérsias acadêmicas durante a última década. O presente artigo, à luz dos teóricos das relações internacionais e da ciência política, analisa a legitimidade dessas atitudes por meio do unilateralismo norte-americano.

\section{Abstract}

Humanitarian interventions (Bosnia, 1995-2003; Somalia, 1992-1993; Kosovo, 1999-2003) and the replacement of dictatorial regimes (Haiti, 1994; Afghanistan, 2001-2003; Iraq, 2003) in international politics have aroused much academic controversy throughout this past decade. This article analyzes, in light of the views of international relations and political science theorists, the legitimacy of such initiatives from the standpoint of the United States' unilateralism.

Palavras-chave: Estados Unidos, Iraque, Intervenção Militar, Organização das Nações Unidas.

Key words: United States; Iraq; military intervention; UN. 